\title{
Some Risk Factors for Hypertension of Khmer People Aged From 25 to 64 Years in Tra Vinh Province, Viet Nam
}

\author{
Tap Nguyen-Van ${ }^{1 *}$, Binh Nguyen-Thanh ${ }^{1}$ and Huong Tran-Van
}

${ }^{1}$ University of Medicine and Pharmacy of Ho Chi Minh City, Vietnam

${ }^{2}$ University of Thang Long, Hanoi, Vietnam

\begin{abstract}
A cross-sectional study was conducted on 1,200 Khmer people aged 25-64 years living in Tra Vinh province to propotion of hypertension some related factors. 30 communes (clusters) were selected by probability proportional to size (PPS) method, evaluating their risk factors of coronary artery disease (CAD) in the next 10 years using Framingham scale in face-to-face interviews. Results showed that propotion of hypertension was $33.5 \%$, inside, having $37.3 \%$ people don't know that they are getting hypertension disease. About some risk factors: $83.6 \%$ of participants had diet with less fat, $26.2 \%$ had adequate fruit and vegetable consumption, $10.6 \%$ had less-salt diet, $85.2 \%$ were non-alcohol abuse, $62.5 \%$ were non-smokers and $79.3 \%$ had moderate physical activity. About coronary artery disease: $79.7 \%$ of respondents have low risk, $16.3 \%$ with moderate risk and $4.0 \%$ with high risk of CAD in the next 10 years according to Framingham scale. The risk increases proportionally to the age and higher among men than women.
\end{abstract}

Keywords: Hypertension; Coronary artery disease; KHMER people

\section{Introduction}

Hypertension and coronary artery disease (CAD) is a common heart disease in developed countries and tends to increase sharply in developing countries. In the world, one out of three deaths is caused by heart diseases [1]. In Vietnam, the mortality rate of CAD is 45 per 100.000 populations [2]. The identified risk factors of hypertension and CAD include age, sex, and family history of the disease, blood lipid disorder, and diet with salty foods, smoking, alcohol abuse, inadequate nutrition, and insufficient physical activity. Tra Vinh is a province, where Khmer people are more populated with limited socio-economic conditions and low utilization of health services. It is necessary to determined proportion of hypertension and evaluates some risk factors and risk of CAD among Khmer people in order to recommend the effective interventions for the improvement of health in this community. The study was conducted to determined proportion of hypertension and evaluates the risk of CAD in the next 10 years among Khmer people aged 25-64 years in Tra Vinh in 2015.

\section{Methods}

\section{Participants and duration}

Participants: Khmer people aged 25-64 years who are permanent residents or temporary residents in at least 1 year, excluding pregnant women, people with foot malformation or osteopathic scoliosis.

Duration: The study was conducted from July to October 2015.

\section{Research design}

A descriptive cross-sectional study

Sample Size:

$n=Z_{(1-\alpha / 2)}^{2} \times\left(\frac{p \times(1-p)}{\varepsilon^{2}}\right) \times D E$

n: minimum sample size

$\mathrm{p}=0.22$.

According report of WHO about the proportion of hypertension in Vietnam, 2014 [3] $\alpha$ : statistical significant level at $95 \%$ level of confidence $(\alpha=0.05)$.

$\varepsilon=0.04$ : acceptable error

Design effect $\mathrm{DE}=2$.

Minimum sample size is $n=1,188$ people.

In fact, we recruited 1,200 people.

Sample selection: 30 clusters by probability proportional to size method.

The cumulative population of Khmer people living in 104 communes of Tra Vinh was 187,096 people aged 25-64 years. In this study, we selected 30 clusters of 40 people in each commune. All Khmer people aged 25-64 years in each communes were listed and classified into 4 age group: $25-34,35-44,45-54,55-64$. We randomly selected 5 men and 5 women in each age group.

Data collection: Interview using structured questionnaire adapted from the tool of World Health Organization. Blood pressures were measured by Microlife BP 3BM1-3.

Total cholesterol, serum triglycerides, HDL-cholesterol were measured by enzymatic end point method using automatic biochemical machine AU680.

Indicators: Diet with salty foods: the consumption of salty foods of 3 days or more per week or of 5 gram or more of salt per day for each person in a household. Diet with plenty of fat: the intake of more

*Corresponding author: A/Pr. Tap Nguyen-Van, MD, PhD, University of Medicine and Pharmacy of Ho Chi Minh City, Vietnam, Tel: +84.914064340; E-mail: ngvtap@ump.edu.vn

Received June 02, 2017; Accepted June 09, 2017; Published June 14, 2017

Citation: Nguyen-Van T, Nguyen-Thanh B, Tran-Van H (2017) Some Risk Factors for Hypertension of Khmer People Aged From 25 to 64 Years in Tra Vinh Province, Viet Nam. J Vasc Med Surg 5: 318. doi: 10.4172/2329-6925.1000318

Copyright: (C) 2017 Nguyen-Van T, et al. This is an open-access article distributed under the terms of the Creative Commons Attribution License, which permits unrestricted use, distribution, and reproduction in any medium, provided the original author and source are credited. 
than $25 \%$ lipid/day and more than $7 \%$ saturated fat or more than $300 \mathrm{gram} /$ person/month or consume animal's fat, lipid in more than 4 days/week. Fruit and vegetable consumption: the intake of 5 units or more of fruit or vegetable per day. Each unit is equivalent to $80 \mathrm{~g}$. Alcohol abuse: drink 5 standard units or more of alcoholic beverage (for men) and 4 standard units or more (for women) on any day in a week (01 standard unit is equivalent to $10 \mathrm{~g}$ ethanol or $330 \mathrm{~mL}$ beer, 30 $\mathrm{mL}$ strong alcoholic drinks, $120 \mathrm{~mL}$ wine). Smoking: current smoking or have been stopped smoking in less than 6 months of any type of cigarette like tobacco, cigar or pipes.

Physical activity: Vigorous physical activity of at least 75 minutes per week or moderate physical activity of at least 150 minutes per week or combination of both vigorous and moderate physical activity of 600 MET-minute per week. Overall good practice: consume less fat, no alcohol abuse, and engage regular physical activity.

The level of CAD risk in the next 10 years using Framingham scale which is based on 5 variables: age, HDL-C level, total cholesterol, smoking, systolic blood pressure. Low risk: $<10 \%$. Moderate risk: $10-$ $20 \%$. High risk: $>20 \%$.

\section{Data analysis}

The data were entered by Epidata software, and analysed by Stata 12 software. $\chi^{2}$ test was used with $p$ value $<0.05$.

\section{Ethical consideration}

The benefits and personal information of the participants are protected according to the regulation of Institutional Review Board of the National Institute of Hygiene and Epidemiology and Tra Vinh Department of Health before implementation.

\section{Results}

\section{Demographical characteristics of Khmer people in Tra Vinh province}

The study included 1200 participants, among those $57.8 \%$ had the education level lower than primary school and $77.7 \%$ were farmers, $42.3 \%$ had the household income between $2,150,000$ to less than $4,300,000 \mathrm{VND}$.

\section{Situation of hypertension of Khmer people in Tra Vinh province}

Result showed 402 people with hypertension disease, proportion was $33.5 \%$; inside, the proportion of hypertension was discovered to be $21.0 \%$, proportion of newly diagnosed with hypertension was $12.5 \%$ (Table 1).

After control impaction of variables together, some factors associated really to proportion of hypertension were sex, age group, diet with less fat, diet with salty foods, fruit and vegetable consumption, alcohol abuse, obesity (Table 2).

\section{Practice of hypertension prevention Khmer people}

The correct overall practice towards hypertension prevention and control accounts for $54.7 \%$ of respondents. The proportion were $10.6 \%$

\begin{tabular}{|l|l|l|l|}
\hline & Hypertension & Freq. & $\%$ \\
\hline No hypertension & & 798 & 66.5 \\
\hline Hypertension & Having been diagnosed & 252 & 21 \\
\cline { 2 - 4 } & Newly diagnosed & 150 & 12.5 \\
\hline
\end{tabular}

Table 1: Propotion of hypertension of Khmer people in Tra Vinh province. for less-salt diet, $83.6 \%$ for no/less-fat diet, $26.2 \%$ for adequate fruit and vegetable consumption, $85.2 \%$ for no alcohol abuse, $62.5 \%$ for no smoking, and $79.3 \%$ for physical activity (Table 3 ).

The of people with correct overall hypertension prevention and control practices is $50.5 \%$ among men that is lower than among women with $58.8 \%, \mathrm{p}<0.05$. The figures are $47.6 \%$ and $56.5 \%$ among people with and without history of hypertension, respectively, $\mathrm{p}<0.05$ (Table 4).

\section{Risk of coronary artery disease and demographical characteristics}

The risk of CAD in the next 10 years is $79.7 \%$ with low risk, $16.3 \%$ with moderate risk and $4.0 \%$ with high risk. Males are more likely to get CAD with $7.9 \%$ than females with $0 \%$ (Table 5 ).

\section{Discussion}

\section{Situation of hypertension among Khmer people at Tra Vinh province}

Result of this study showed that proportion of pretension among Khmer people at Tra Vinh province was 33.5\%, inside; having $37.3 \%$ people don't know that they are getting hypertension disease. This result higher when compared with report of Viet Nam Ministry of Health, the proportion hypertension among Khmer people from 25 years or older was $25.1 \%$ (2012-2015). Hypertension is rapidly increasing in Tra Vinh province and the increase in Khmer people is higher than in other communities.

\begin{tabular}{|c|c|c|c|}
\hline Factors & $\begin{array}{l}\text { Cruve-OR } \\
(95 \% \mathrm{Cl})\end{array}$ & $\begin{array}{l}\text { Combined-OR } \\
(95 \% \mathrm{Cl})\end{array}$ & p-value \\
\hline Sex & $1.4(1.1-1.8)$ & $1.7(1.2-2.4)$ & $<0.05$ \\
\hline \multicolumn{4}{|l|}{ Age groups } \\
\hline $25-34$ & 1 & 1 & 1 \\
\hline $35-44$ & $2(1.3-3.0)$ & $2.1(1.3-3.3)$ & $<0.05$ \\
\hline $45-54$ & $3.6(2.5-5.2)$ & $5.1(3.3-8.0)$ & $<0.05$ \\
\hline $55-64$ & $4.9(3.4-7.0)$ & $9.0(5.8-14.0)$ & $<0.05$ \\
\hline Diet with less fat & $1.9(1.4-2.6)$ & $1.7(1.2-2.4)$ & $<0.05$ \\
\hline $\begin{array}{l}\text { Fruit and vegetable } \\
\text { consumption }\end{array}$ & $2.3(1.2-4.5)$ & $2.2(1.1-4.6)$ & $<0.05$ \\
\hline Diet with salty foods & $2.1(1.3-3.3)$ & $1.4(1.1-2.1)$ & $<0.05$ \\
\hline Alcohol abuse & $1.5(1.1-2.1)$ & $1.6(1.1-2.4)$ & $<0.05$ \\
\hline Smoking & $1.4(1.1-1.8)$ & $0.8(0.6-1.2)$ & $>0.05$ \\
\hline Dyslipidemia & $2.0(1.6-2.6)$ & $1.3(0.9-1.7)$ & $>0.05$ \\
\hline Obesity & $2.6(1.9-3.5)$ & $2.3(1.7-3.3)$ & $<0.05$ \\
\hline Glucose disorder & $2.3(1.5-3.6)$ & $1.4(0.9-2.1)$ & $>0.05$ \\
\hline
\end{tabular}

Table 2: Some risk factors of hypertension among Khmer people through multivariate analysis.

\begin{tabular}{|l|c|c|c|c|}
\hline \multirow{2}{*}{ Practice } & \multicolumn{2}{|c|}{ Correct } & \multicolumn{2}{c|}{ Incorrect } \\
\cline { 2 - 5 } & Freq. & $\%$ & Freq. & $\%$ \\
\hline Diet with less fat & 1003 & 83.6 & 197 & 16.4 \\
\hline Fruit and vegetable consumption & 314 & 26.2 & 886 & 73.8 \\
\hline Diet with salty foods & 127 & 10.6 & 1073 & 89.4 \\
\hline Alcohol abuse & 1022 & 85.2 & 178 & 14.8 \\
\hline Smoking & 750 & 62.5 & 450 & 37.5 \\
\hline $\begin{array}{l}\text { Moderate or vigorous physical } \\
\text { activity in more than 150 minutes } \\
\text { per week }\end{array}$ & 952 & 79.3 & 248 & 20.7 \\
\hline $\begin{array}{l}\text { Regular health check } \\
\text { Receipt of information related to } \\
\text { hypertension }\end{array}$ & 585 & 48.8 & 615 & 51.3 \\
\hline
\end{tabular}

Table 3: Practice of hypertension prevention among Khmer people $(n=1.200)$. 
Citation: Nguyen-Van T, Nguyen-Thanh B, Tran-Van H (2017) Some Risk Factors for Hypertension of Khmer People Aged From 25 to 64 Years in Tra Vinh Province, Viet Nam. J Vasc Med Surg 5: 318. doi: 10.4172/2329-6925.1000318

Page 3 of 5

\begin{tabular}{|c|c|c|c|c|c|c|}
\hline \multirow[t]{2}{*}{ Associated factors } & & \multicolumn{2}{|c|}{ Correct overall practice } & \multirow[t]{2}{*}{ Total } & \multirow[t]{2}{*}{$p$-value } & \multirow[t]{2}{*}{ OR $(95 \% \mathrm{Cl})$} \\
\hline & & Freq. & $\%$ & & & \\
\hline \multirow[t]{2}{*}{ Sex } & Female & 353 & 58.8 & 600 & \multirow[t]{2}{*}{$<0.05\left(^{*}\right)$} & 1 \\
\hline & Male & 303 & 50.5 & 600 & & $0.71(0.56-0.90)$ \\
\hline \multirow[t]{4}{*}{ Age group } & 25-34 & 168 & 56 & 300 & & 1 \\
\hline & $35-44$ & 153 & 51 & 300 & $>0.05$ & $0.82(0.59-1.13)$ \\
\hline & 45-54 & 172 & 57.3 & 300 & $>0.05$ & $1.06(0.76-1.46)$ \\
\hline & $55-64$ & 163 & 54.3 & 300 & $>0.05$ & $0.93(0.68-1.29)$ \\
\hline \multirow[t]{3}{*}{ Occupation } & Farmers & 522 & 56 & 932 & & 1 \\
\hline & $\begin{array}{l}\text { Blue- or white- collar } \\
\text { workers }\end{array}$ & 22 & 53.7 & 41 & $>0.05$ & $0.91(0.48-1.70)$ \\
\hline & Others $^{*}$ & 112 & 49.3 & 227 & $>0.05$ & $0.76(0.57-1.02)$ \\
\hline \multirow[t]{5}{*}{ Education level } & $\begin{array}{l}\text { Lower than primary } \\
\text { school }\end{array}$ & 387 & 55.8 & 694 & & 1 \\
\hline & Primary school & 169 & 53.8 & 314 & $>0.05$ & $0.92(0.71-1.21)$ \\
\hline & Secondary school & 75 & 56 & 134 & $>0.05$ & $1.01(0.69-1.46)$ \\
\hline & High shool & 16 & 38.1 & 42 & $>0.05$ & $0.48(0.26-0.93)$ \\
\hline & Higher than high school & 9 & 56.2 & 16 & $>0.05$ & $1.02(0.37-2.77)$ \\
\hline \multirow{5}{*}{$\begin{array}{l}\text { Household income (million } \\
\text { dong) }\end{array}$} & $<2.15$ & 226 & 53.4 & 423 & & 1 \\
\hline & $2.15-<4.30$ & 266 & 52.4 & 508 & $>0.05$ & $0.96(0.74-1.24)$ \\
\hline & $4.3-6.45$ & 97 & 62.2 & 156 & $>0.05$ & $1.43(0.98-2.09)$ \\
\hline & $6.45-<8.60$ & 32 & 64 & 50 & $>0.05$ & $1.55(0.84-2.85)$ \\
\hline & $\geq 8.60$ & 35 & 55.6 & 63 & $>0.05$ & $1.09(0.64-1.85)$ \\
\hline \multirow[t]{2}{*}{ History of hypertension } & No & 536 & 56.5 & 948 & \multirow[t]{2}{*}{$<0.05\left(^{*}\right)$} & 1 \\
\hline & Yes & 120 & 47.6 & 252 & & $0.70(0.52-0.93)$ \\
\hline \multirow[t]{2}{*}{ Obesity } & No & 551 & 55.3 & 997 & \multirow[t]{2}{*}{$>0.05$} & 1 \\
\hline & Yes & 105 & 51.7 & 203 & & $0.87(0.63-1.19)$ \\
\hline
\end{tabular}

Table 4: Some associated factors of practices towards hypertension prevention.

\begin{tabular}{|c|c|c|c|c|c|c|c|c|c|}
\hline \multirow{3}{*}{\begin{tabular}{|l|} 
Factors \\
Overall \\
\end{tabular}} & & \multicolumn{6}{|c|}{ Risk of CAD } & \multirow{3}{*}{$\begin{array}{l}\text { Total } \\
1200\end{array}$} & \multirow[t]{3}{*}{$\mathbf{p}$} \\
\hline & & \multicolumn{2}{|c|}{ Low } & \multicolumn{2}{|c|}{ Moderate } & \multicolumn{2}{|c|}{ High } & & \\
\hline & & 957 & 79.7 & 196 & 16.3 & 47 & 4 & & \\
\hline \multirow[t]{2}{*}{ Sex } & Female & 583 & 97.1 & 17 & 2.8 & 0 & 0 & 600 & \multirow[t]{2}{*}{$<0.01$} \\
\hline & Male & 374 & 62.3 & 179 & 29.8 & 47 & 7.9 & 600 & \\
\hline \multirow[t]{4}{*}{ Age group } & $25-34$ & 299 & 99.7 & 1 & 0.3 & 0 & 0 & 300 & \multirow[t]{4}{*}{$<0.01$} \\
\hline & $35-44$ & 279 & 93 & 18 & 6 & 3 & 1 & 300 & \\
\hline & $45-54$ & 220 & 73.3 & 67 & 22.3 & 13 & 4.4 & 300 & \\
\hline & $55-64$ & 159 & 53 & 110 & 36.7 & 31 & 10.3 & 300 & \\
\hline \multirow[t]{5}{*}{ Education level } & Able to read and write & 548 & 78.9 & 121 & 17.4 & 25 & 3.7 & 694 & \multirow[t]{5}{*}{0.61} \\
\hline & Primary school & 248 & 78.9 & 51 & 16.2 & 15 & 4.9 & 314 & \\
\hline & Secondary school & 110 & 82.1 & 19 & 14.2 & 5 & 3.7 & 134 & \\
\hline & High school & 35 & 83.3 & 5 & 11.9 & 2 & 4.8 & 42 & \\
\hline & Higher than high school & 16 & 100 & 0 & 0 & 0 & 0 & 16 & \\
\hline \multirow[t]{3}{*}{ Occupation } & Blue- or white- collar workers & 35 & 85.4 & 3 & 7.3 & 3 & 7.3 & 41 & \multirow[t]{3}{*}{0.27} \\
\hline & Farmers & 735 & 78.9 & 160 & 17.2 & 37 & 3.9 & 932 & \\
\hline & Others* & 187 & 82.4 & 33 & 14.5 & 7 & 3.1 & 227 & \\
\hline \multirow[t]{5}{*}{ Household income (million dong) } & $<2.15$ & 317 & 79.7 & 69 & 17.3 & 12 & 3 & 423 & \multirow[t]{5}{*}{0.44} \\
\hline & $2.15-<4.30$ & 407 & 80.1 & 78 & 15.4 & 23 & 4.5 & 508 & \\
\hline & $4.30-<6.45$ & 123 & 78.9 & 28 & 17.9 & 5 & 3.2 & 156 & \\
\hline & $6.45-<8.60$ & 42 & 84 & 8 & 16 & 0 & 0 & 50 & \\
\hline & $\geq 8.60$ & 51 & 80.9 & 7 & 11.1 & 5 & 8 & 63 & \\
\hline
\end{tabular}

*Other occupations include: sellers, housewives, students, retired people and unemployed (able/unable to work).

Table 5: Risk of CAD according demographical characteristics.

Among 35 INTERSALT Populations with Allele Frequency Data, with an increase of one degree of latitude north or south, populationaverage systolic blood pressure increased by $0.3 \mathrm{mmHg}$. When GNB3 ( $G$ protein $\beta 3$ subunit) $825 \mathrm{~T}$ was included in the analysis, we were able to explain $64 \%$ of worldwide variation in blood pressure. With each $1 \%$ increase in GNB3 825T allele frequency, blood pressure increased $0.19 \mathrm{mmHg}$ [4]. The genetic basis of blood pressure variation is largely unknown but is likely to involve genes. The research in Kenya-Africa, have a total of 1528 adults were surveyed with a mean age of 46.7 years, the age-standardized prevalence of hypertension was $29.4 \%$ (95\% CI 27.0-31.7) [5]. The same, the survey in sub-Saharan Africa shown that the age-standardized prevalence of hypertension ranged from $19.3 \%$ to $38.0 \%$, with the mean age ranged from 36.8 years to 45.3 years [6]. Thus, 
the prevalence of hypertension in some ethnic minority communities is higher than in other communities.

Result this study showed that through multivariate, some factors associated really to proportion of hypertension were sex, age group, diet with less fat, diet with salty foods, fruit and vegetable consumption, alcohol abuse, obesity. Therefore, in interventions for the prevention of hypertension, attention should be paid to these factors.

\section{Some risk factors of hypertension among Khmer people at Tra Vinh province}

The correct overall practice of hypertension prevention and control among Khmer people accounts for $54.7 \%$ of respondents that is associated with sex, history of hypertension. More women than men have correct practices with $58.8 \%$ and $50.5 \%$, respectively. The proportion of hypertension of male higher than female is 1.3 times $\mathrm{p}<0.01$. Young women tend to have lower blood pressure, and less risk of hypertension, compared to young men. As people age, both blood pressure and the risk of hypertension increase in both sexes; this occurs most strikingly in women after menopause [7].

The majority of hypertension case was in age group of 55-64 years with $57.0 \%$, the poorer health of those people in this age leads to the difficulties in physical activity so that the lower of correct practice was seen among those who had been diagnosed with hypertension (47.6\%) than people without or had not been diagnosed with hypertension (56.5\%).

About $16.4 \%$ of Khmer people in this study had the diet with plenty of animal's fat. In contrast, the majority of Khmer people are farmers with lower socio-economic sources so that they have less opportunity to expose to fast foods. Thus, Khmer people have diet with less fat than Kinh people and other ethnicities living in other cities.

The intake significantly depends on the household's economic. Although Tra Vinh is an agricultural province, the daily diet contains many natural vegetables. However, $77.5 \%$ of people participated in this survey have the income lower than 4.300.000 VND that hinders the access to vegetables and fruits to supplement daily diet. In the OHASAMA study, during 4-year follow-up period, After adjustment for all putative confounding factors, the highest quartile of fruit intake was associated with a significantly lower risk of future home hypertension (OR $0.40,95 \%$ CI $0.22-0.74, p=0.004$ ). In conclusion, this study, based on home blood pressure measurement, suggests that higher intake of fruit is associated with a lower risk of future home hypertension [8].

The commonly consumed foods in this region are fish and other seafood using to produce fish-sauce. The diet with salty foods is an important factor of hypertension. It suggests the needs of other intervention measures to improve the knowledge and practice in terms of reducing salt consumption among Khmer people, and thus contribute to hypertension prevention and control.

The alcohol consumption among Khmer people in this study is as twice as in other studies on Kinh people. The drinking habit is determined by social norms, economic conditions and especially local customs and festivals. In a study to appear in Alcoholism: Clinical and Experimental Research, Charles Holahan, who is professor of psychology at The University of Texas at Austin. The researchers followed 1,824 older adults, also found those who drank moderately were more likely to live longer across a 20 -year follow-up than those who drank heavily or who didn't drink at all. The findings showed increases in mortality risk of $42.0 \%$ for heavy drinkers and $49.0 \%$ for abstainers in comparison to moderate drinkers [9]. This study of among Khmer people shown that proportion of alcohol abuse is $14.8 \%$, alcohol abuse in the Khmer youngers are highest and lasted many years can cause hypertension when older.

In this study, $32.0 \%$ of participants are smokers, of which $61.3 \%$ in males and $2.7 \%$ in females $(P R=23 ; \mathrm{p}<0.05)$. Furthermore, the smoking initiation among Khmer people is Tra Vinh is very early. Among the smokers, $84.6 \%$ have experienced smoking more than 10 years with the mean age of $22.2 \pm 11.3$ years. $36.2 \%$ smoke less than 10 cigarettes per day, $39.4 \%$ smoke from 10 to less than 20 cigarettes per day and $24.4 \%$ smoke 20 or more cigarettes per day.

The people who meet the recommended physical activity are $79.3 \%$, which is mostly due to the works of farmers that require more physical activity (77.7\% of respondents are farmers). $20.7 \%$ of Khmer people have physical inactivity. The distinction may be explained that the above ethnic people live in mountainous areas that they have to climb the mountains while carrying heavy tools to do farm works. This is why their physical activity is more intense than Khmer people living in delta areas. In study in Kenya, when fit in a multivariable logistic regression model, moderate physical activity $[\mathrm{AOR}=1.9 ;(95 \% \mathrm{CI}, 1.2$ 3.0)], remained significantly associated with hypertension [5]. A metaanalysis of prospective cohort studies in China, including 136,846 persons who were initially free of hypertension, and 15607 persons developed hypertension during follow-up. The pooled relative risk of main results from these studies suggests that both high and moderate levels of recreational physical activity were associated with decreased risk of hypertension (high vs. low: RR, 0.81; 95\%CI, 0.76-0.85 and moderate versus low: $\mathrm{RR}=0.89$; $95 \% \mathrm{CI} 0.85-0.94$ ) [10].

\section{The risk of CAD in the next 10 years of Khmer people}

According to Framingham scale, the risk of CAD in the next 10 years of Khmer people is $79.7 \%$ with low risk, $16.3 \%$ with moderate risk and $4.0 \%$ with high risk. CAD is a common disease among elderly people and resulted from many factors like high blood pressure, and particularly, blood lipid disorder. At the same time, the older people are not easy to convince to change in lifestyle and habits like smoking that occur with physical inactivity and low health care accountability. Thus, the elderly people have higher risk than younger adults.

To sum up, among Khmer people participated in this study, there are 956 people at low risk, 196 people at moderate risk and 48 people with high risk of CAD. The inference in $187,096 \mathrm{Khmer}$ people aged 25-64 years living in Tra Vinh province in 2015 is that there will have been 7.484 Khmer people at high risk of CAD by 2025 .

Age is an important factor of atherosclerosis. CAD develops silently and slowly in many years from young age. After a long time, the arteries are aging, hardening and loss of elasticity. The risk of CAD in the next 10 years by Framingham scale among study participants increases proportionally to age with statistical significance $(\mathrm{p}<0.01)$ The high risk of CAD in 10 coming years is highest among people aged 55-64 years with $10.3 \%$. A cross-sectional study conducted on 13,769 adult people aged 20-79 years in the United States in 2004 also indicates that the older a person is, the higher risk of CAD in 10 years does the person get with $p<0.05$ [11]. It means that age is a risk factor of CAD that cannot be modified by medical intervention but it is valuable in CAD prediction among Khmer people in Tra Vinh.

Males are more likely to develop CAD than females with $7.9 \%$ and $0 \%$, respectively. Besides, the moderate risk accounts for $29.8 \%$ among 
males and $2.8 \%$ among females. The results are in line with a cohort study of Framingham that follows up 5251 white people in 10 years. The CAD was found in $8.0 \%$ of males and $2.8 \%$ of females [12]. In one hand, the arteries are ageing more quickly among males than females. On the other hand, the estrogen hormone helps protect the women against CAD. It is demonstrated that the risk of CAD is reduced by $35-$ $50 \%$ with estrogen supplementation. This is explained that estrogen is conducive to the increase of HDL-C, decrease of LDL-C and lipoprotein (a) and accelerates the LDL-C oxidation.

This study cannot indicate the association between CAD risk in the next 10 years and education level, occupation and income. The factors considered in CAD risk evaluation are less likely to be influenced by level, occupation and income. It is necessary to conduct cohort studies to identify the association between those factors and CAD in the next 10 years.

\section{Conclusions}

Proportion of pretension was $33.5 \%$, inside; having $37.3 \%$ people don't know that they are getting hypertension disease. About some risk factors have related to the diet with less fat, adequate fruit and vegetable consumption, less-salt diet, alcohol abuse, smokers and physical activity. About coronary artery disease have the moderate risk (16.3\%) and high risk (4.0\%) of CAD in the next 10 years according to Framingham scale. The risk increases proportionally to the age and higher among men than women.

\section{Disclosure}

The authors declare no conflicts of interest.

\section{References}

1. Lozano R, Naghavi M, Foreman K, Lim S, Shibuya K, et al. (2012) Global and regional mortality from 235 causes of death for 20 age groups in 1990 and 2010: a systematic analysis for the Global Burden of Disease Study 2010 Lancet 380: 2095-128.

2. World Health Organization (2014) Viet nam: coconary heart disease.

3. WHO (2015) Global Status report on noncommunicable diseases 2014 Switzerland; pp: 264-271

4. Young JH, Chang YP, Kim JD, Chretien JP, Klag MJ, et al. (2005) Differentia susceptibility to hypertension is due to selection during the out-of-africa expansion. The Evolution of Hypertension 1: 730-738.

5. Olack B, Wabwire-Mangen F, Smeeth L, Montgomery JM, Kiwanuka N, et al. (2015) Risk factors of hypertension among adults aged 35-64 years living in an urban slum Nairobi, Kenya. BMC Public Health 15: 1-9.

6. Hendriks ME, Wit FW, Roos MT, Brewster LM, Akande TM, et al. (2012) Hypertension in sub-saharan africa: cross-sectional surveys in four rural and urban communities. PLoS ONE 7: 1-10.

7. Hart EC, Joyner MJ, Wallin BG, Charkoudian N (2012) Sex, ageing and resting blood pressure: gaining insights from the integrated balance of neural and haemodynamic factors. The Journal of Physiology 590: 2069-2079.

8. Tsubota-Utsugi M, Ohkubo T, Kikuya M, Metoki H, Kurimoto A, et al. (2011) High fruit intake is associated with a lower risk of future hypertension determined by home blood pressure measurement: the ohasama study. Journal of Human Hypertension 25: 164-171.

9. Holahan C (2010) Moderate drinking helps middle-aged and older people live longer, research shows. UT News The University of Texas at Austin, England.

10. Huai P, Xun H, Reilly KH, Wang Y, Ma W, et al. (2013) Physical activity and risk of hypertension a meta-analysis of prospective cohort studies. Hypertension 62: $1021-1026$

11. Ford ES, Giles WH, Mokdad AH (2004) The distribution of 10 -Year risk for coronary heart disease among US adults: findings from the National Health and Nutrition Examination Survey III. J Am Coll Cardiol 43: 1791-1796.

12. Wilson PW, D’Agostino RB, Levy D, Belanger AM, Silbershatz H, et al. (1998) Prediction of coronary heart disease using risk factor categories. Circulation 97: 1837-1847. 